\title{
El libro como objeto de estudio: un marco historiográfico para la Nueva Granada
}

Old books as an object of study: a historiographical frame for Nueva Granada

\author{
Alfonso RUBIO HERNÁNDEZ \\ Grupo de investigación Nación-Cultura-Memoria, Departamento de Historia, Facultad de Humanidades, \\ Universidad del Valle, Colombia, alfonru@telmex.net.co
}

\begin{abstract}
Resumen
A manera de propuesta investigativa se sintetizan algunos planteamientos historiográficos sobre el estudio del libro que permitan rastrear su circulación, la práctica y los usos de su lectura, para centrar y desentrañar sus implicaciones políticas, sociales y culturales en Nueva Granada, e intentar comprender la denominada historia social de la cultura escrita de una época que va del siglo XVI al XVIII, primando la investigación del gran potencial que poseen las fuentes originales de archivo y el propio "libro antiguo" desde los todavía necesarios análisis cuantitativos.
\end{abstract}

Palabras clave: Historiografía. Nueva Granada, Bibliotecas. Libro antiguo. Cultura escrita.

\section{Introducción}

En el siglo XVI se extiende y generaliza la imprenta, la invención que ofrece una nueva manera de escribir; se consolida la Reforma y se institucionaliza la censura de libros, reglamentando su ejercicio por medio de la publicación sucesiva de índices de libros prohibidos. Estos hechos están relacionados y explican los procesos de la presencia y circulación de textos en la Europa moderna y en América desde perspectivas históricas, políticas, teológicas o literarias que necesariamente deben considerar al libro como objeto de estudio, un libro que muy tempranamente, desde que se crea la Real Audiencia del Nuevo Reino de Granada, vino a ocupar numerosos y variados tipos de bibliotecas.

Estas bibliotecas o colecciones de lo que ahora podemos llamar "libros antiguos", formadas por particulares, instituciones públicas u órdenes religiosas que durante la época colonial se trasladaron desde España al territorio americano, encierran una gran riqueza como fuente para el historiador. A través de ellas podemos reconstruir la comunidad de lectores, quiénes leían y qué leían. Son igualmente un reflejo de lo que se publicaba, lo que circulaba, las preocupaciones de una profesión, de una comunidad, de una época y, de alguna manera, dan testimonio de la formación de un espacio público y su influencia cultural. Nos permiten, además, obser-

\begin{abstract}
Some historiographic approaches for studying the circulation, reading and uses of books in Nueva Granada in the Modern Age are presented, that may be useful to discern their social, political and cultural implications for the history of this region of Colombia.
\end{abstract}

Keywords: Historiography. Nueva Granada (Colombia). Libraries. Books. Old books. Literate culture.

var los intercambios culturales internacionales, el movimiento de las ideas, las influencias tanto en el fondo como en la forma de los libros, o la historia de los talleres tipográficos o casas editoriales, ya que el libro no sólo es un objeto cultural, sino también una mercancía.

En colaboración con la Biblioteca Mario Carvajal, de la Universidad del Valle, producto de una mayor investigación entorno al Proyecto que denominamos Catalogación de la colección de libros antiguos de la Biblioteca Central de la Universidad del Valle (Santiago de Cali. Colombia), presentamos aquí un texto que se detiene en el libro como objeto de estudio desde las actuales perspectivas de la Historia social de la cultura escrita.

\section{El libro como objeto de estudio: un marco historiográfico para la Nueva Granada}

La obra L'apparition du livre, de Henri-Jean Martin y Lucien Febvre, publicada en 1958 estudia "la acción cultural y la influencia del libro" desde mediados del siglo XV hasta las últimas décadas del XVIII. Considerado como uno de los medios más poderosos de los que ha podido disponer la civilización de Occidente para "concentrar el pensamiento disperso de sus representantes" y "dominar sobre el mundo", la obra, 
concebida por Febvre y desarrollada por Martin, define el alcance (siendo ésta su novedad) de ese papel de dominio que desempeñó el libro, e intenta, al mismo tiempo, crear entre los estudiosos "nuevos hábitos de trabajo intelectual" (Febvre y Martin, 1962, p. XVIII y XIX). A partir de su publicación, ciertamente, el conocimiento histórico de las formas de la cultura escrita ha alcanzado un notable desarrollo. Desde entonces, la variedad de planteamientos historiográficos sobre el "libro" y la "biblioteca", así como sus resultados, han puesto de manifiesto el gran potencial que poseen las fuentes originales (mayoritariamente documentación de archivo y los propios "libros antiguos") para contribuir a la comprensión de la historia cultural de una época que entraña una dificultad intrínseca, pues el mismo objeto de estudio es complejo de comprender desde su materialidad y sus relaciones en la historia en tanto mercancía producida dentro de un contexto comercial y como signo cultural, soporte de un sentido que transmite el texto o la imagen y que define a la sociedad y a su poseedor (Chartier y Roche, 1974, p. 115137) (1).

Los trabajos de J. H. Martin y François Furet y su equipo pusieron las bases de una historia cuantitativa del libro con las que todavía hoy se desarrollan rigurosos análisis para desentrañar los valores culturales de las sociedades en el Antiguo Régimen. Las décadas de los años ochenta y los noventa, como nos lo hace saber Manuel Peña Díaz (1997, p. 33), han supuesto una constante renovación de la historia de la cultura del impreso en Europa y Norteamérica, y en este contexto internacional sobresalen las reflexiones de Roger Chartier sobre lo que denomina las "prácticas de la lectura".

Apoyándose en las sugerencias de Michel de Certeau (L'Invention du quotidien), su objetivo como historiador es el de articular tres polos distintos bajo la asociación de la crítica textual, la bibliography y la historia cultural (Chartier, 1995, p. 107-120 y 1996, p. 24-30):

1. El análisis de los textos descifrados en sus estructuras, motivos y alcances.

2. La historia de los libros, de todos los objetos y de todas las formas que vehiculan lo escrito. Una historia de los libros definida por la relación entre el texto, el libro y la lectura, que comprenda cómo los mismos textos pueden ser diversamente aprehendidos, manejados y comprendidos; que reconstruya las redes de prácticas que organizan los modos, histórica y socialmente diferenciados del acceso a los textos, poniendo atención particularmente en las maneras de leer; y teniendo en cuenta que no hay texto fuera del soporte que lo da a leer (o a escuchar) y que por tanto no hay comprensión de un escrito que no dependa en alguna medida de su materialidad.

\section{El estudio de las prácticas que se hacen cargo de esos objetos o formas, produciendo usos y significaciones diferenciadas}

Relacionando la historia de los textos, la historia de las formas de comunicación y la historia de las prácticas culturales, comenzando por la lectura; y utilizando conceptos como "configuración", "apropiación diferenciada", "producción de sentido", Chartier acuña el término de "historia cultural de lo social", donde el concepto de "cultura" es entendido como un conjunto de prácticas y representaciones por las cuales el individuo forma el sentido de su existencia a partir de necesidades sociales concretas; prácticas y representaciones, señala Ricardo García Cárcel (1995, p. 10), que llevan a superar al autor una serie de dicotomías: el dualismo objetividadsubjetividad; la confrontación producciónconsumo o la contraposición culto-popular.

En este enfoque historiográfico sobre la práctica y usos de la lectura, abriendo nuevas perspectivas y utilizando nuevas fuentes, se sitúan los estudios de historiadores alemanes, ingleses, españoles y la abundante producción historiográfica italiana que, a fines de los años setenta, acuñó el término de Historia de la Cultura Escrita bajo la influencia de la "nueva paleografía", un movimiento de renovación conceptual y metodológico en la disciplina paleográfica donde podemos situar a los profesores Armando Petrucci y Attilio Bartoli Langeli.

Para Petrucci (2003, p. 7-9), identificando el ámbito de investigación en negativo, la "historia de la cultura escrita" no es la historia del libro o del documento; no es historia de los textos; no es historia de la cultura intelectual; no es historia de las culturas subalternas, ni tampoco, en sentido estricto, historia de la escritura o de las escrituras. Planteando un método indiciario, de relevamiento y de análisis formal y comparativo de las características gráficas y materiales de los testimonios escritos, el paleógrafo italiano reivindica una disciplina que se configure como una auténtica historia de la cultura escrita y que se ocupe de la historia de la producción, de las características formales y de los usos sociales de la escritura y de los testimonios escritos en una sociedad determinada, independientemente de las técnicas y los materiales utilizados. 
Antonio Castillo Gómez (1994, p. 133-168 y 2002, p. 15-25), por su parte, planteando un método que puede aunar a cuantas disciplinas tengan como objeto el estudio de la escritura, propone la superación de esa distinción convencional entre la historia de la escritura, por un lado, y la historia del libro y de la lectura, por otro, para hacerlas converger en un espacio común: el de la Historia Social de la Cultura Escrita, cuyo cometido sería el estudio de la producción, difusión, uso y conservación de los objetos escritos, cualquiera que sea su concreta materialidad (del documento oficial a la carta privada) o soporte (de la tablilla de arcilla a la pantalla electrónica).

Para él, el momento actual de la historia social de la cultura escrita está determinado por tres conceptos, los discursos, las prácticas y las representaciones; e interesa indagar en:

1. Lo que la escritura ha supuesto para las distintas sociedades y, dentro de estas, para las diferentes clases sociales.

2. Las concretas maneras de escribir y de leer, y en las prácticas a que han dado lugar, desde la escritura oficial a la personal, desde la inscripción al diario, desde el manuscrito iluminado al libro de bolsillo, desde el códice al e-book, desde la lectura en alta voz a la silenciosa, desde la de gabinete a la de plaza.

3. Las varias imágenes, artísticas y literarias, que cada sociedad ha elaborado de los productos escritos, ya que pueden reflejar una cierta realidad o bien una determinada mentalidad.

La importancia que la historia de la cultura escrita otorga a la materialidad de los objetos escritos (no tanto para describirlos técnicamente desde disciplinas como la paleografía o la diplomática, cuanto para desentrañar la relación que existe entre las estrategias materiales y las apropiaciones) es lo que singularizaría a la "historia de la cultura escrita" respecto a otras formas de hacer la historia, especialmente respecto a la historia cultural.

El término Historia Social de la Cultura Escrita es también utilizado por el profesor Francisco Gimeno Blay (1999) como el campo donde confluyen dos líneas de trabajo: el estudio de las "prácticas de escritura y las prácticas de lectura", preconizado por el profesor Armando Petrucci y el de la "historia cultural de lo social", propuesto por el profesor Roger Chartier.

Es el caso, como ejemplo reciente en países de la América hispana de análisis que continúan estos mismos enfoques, de los seis ensayos del argentino Alejandro E. Parada reunidos en el volumen titulado Cuando los lectores nos susurran. Libros, lecturas, bibliotecas, sociedad y prácticas editoriales en la Argentina. En su conjunto, así nos lo hace saber el propio autor, la obra, teóricamente se enmarca en las tendencias modernas de la historiografía sobre la lectura, inmersa en el campo de la Nueva Historia Cultural, título del ya clásico libro editado y prologado por Lynn Hunt en 1989 y, posteriormente, influida por las contribuciones de Peter Burke, Roger Chartier, Robert Darnton, Carlo Ginzburg, D.F. McKenzie y Armando Petrucci.

La obra de Parada intenta rescatar la "difusa presencia" de los lectores argentinos en distintos momentos del siglo XIX y XX y nos advierte (es un rasgo común a la hora de afrontar estudios que tienen como objeto el libro o el impreso en general) de su dificultad y complejidad, pues las formas de llegar a la letra impresa "son polisemánticas, solapadas, abigarradas en textualidades semiocultas, disfrazadas en otras prácticas y, sobre todo, impregnadas por sutiles representaciones que tejen un conjunto de infinitas dificultades" (Parada, 2007, p. 15-16).

Para Teodoro Hampe Martínez (1996, p. 18-19), la historia del libro en la Hispanoamérica colonial puede ser emprendida, al menos, desde tres perspectivas distintas:

1. Una perspectiva que analice los factores ideológicos del libro como reflejo de una determinada mentalidad en la sociedad colonial, la difusión de ideas o sus repercusiones en la construcción de determinados comportamientos sociales y políticos; el libro, en palabras de Febvre y Martin, "como fermento".

2. Otra sería la mercantil, que estudiaría aspectos de la producción, el comercio y la circulación de libros, trazando rutas de distribución y analizando tanto el ámbito privado como el de las instituciones públicas y religiosas.

3. Y la tercera sería la tecnológica, interesada en el desarrollo de la tipografía. Estudiaría la materialidad de lo que ya hoy consideramos "libro antiguo". Una materialidad enmarcada en lo que François Géal (Figures de la bibliothèque dans l'imaginaire espagnol du Siècle d'Or) denomina las "representaciones imaginarias" de la biblioteca, que relacionan los libros con una construcción jerárquica de los saberes y una memoria colectiva.

El estado actual de las investigaciones manifiesta un predominio casi absoluto de la literatura de carácter religioso en las sociedades hispanizadas de los siglos XVI y XVII. Sociedades sacralizadas donde las manifestaciones de la vida humana estaban mediatizadas por la creencia 
religiosa. La religión dictaba las normas de convivencia y delimitaba las formas de relación con el poder. La formación del hábito de la lectura y de un público lector más amplio, por tanto, tiene orígenes religiosos entrelazados a factores jurídicos, sociales y económicos. El estudio de la sociedad colonial, sugiere Gutiérrez Girardot (1989, p. 32-33), será esencial no sólo para que una historia social de la literatura no sea fragmentaria, sino para comprender el surgimiento de una "nueva sociedad" en la europeización del Nuevo Mundo. La historia de la lectura, de la formación de un público lector, de la legislación sobre la imprenta y los libros, precisamente, "permitirá esclarecer los mecanismos mediante los cuales se arraigó en esa 'nueva sociedad' una visión teológica del mundo que con rasgos feudales esenciales, es decir, con rasgos europeos, acuñó fuertemente la estructura social y las formas de vida de Latinoamérica" (2).

Guiado por el sociólogo del libro Guillermo Márquez Cruz (1988, p. 9 y ss.) (3), Genero Luis García (2003-04, p. 259-263) recoge sus propuestas de los años ochenta del siglo XX para un estudio del libro, que tenga en cuenta los siguientes elementos de análisis: el marco sociopolítico y jurídico, el marco económico, los mediadores y los receptores.

En el marco sociopolítico y jurídico habría que estudiar la influencia del sistema político e ideológico y su repercusión en el libro a través de la legislación que conlleva unas determinadas políticas culturales encauzadas y ejecutadas por ciertos organismos institucionalizados.

En el marco económico habría que detenerse en los autores y su nivel de profesionalización en relación con el concepto de derechos de autor, en el entramado editorial, en los cambios tecnológicos de la edición del libro, en los aspectos comerciales y jurídicos de la imprenta, en la influencia de los impresores extranjeros y en el estudio de los propios contenidos que se escriben, se publican y se conservan y difunden en las bibliotecas.

En cuanto a los mediadores habría que analizar a los distribuidores y libreros, las formas cambiantes de la distribución: los fascículos y la venta por entregas, los libros de bolsillo, las colecciones adecuadas a públicos concretos, la venta en kioscos, etc.; y por otro lado, las bibliotecas y los bibliotecarios, la regulación de un sistema bibliotecario, su estatus y formación.

Y en relación a los receptores de libros, sus lectores, se podrían analizar sus niveles de alfabetización y las motivaciones para leer: aprendizaje, medio de ejercer una profesión, placer, costumbre, estatus social, etc.
La mayor parte de los estudios se centra en alguna o algunas de estas cuestiones concretas, pero, realmente, para analizar la significación del libro o el impreso en general en una determinada sociedad y época, habría que estudiar la alfabetización, la industria editorial, el comercio librero, la posesión del libro, los tipos de lectores y el autor; o sea, los cuatro grandes grupos propuestos por Márquez Cruz (sociopolítico y jurídico, económico, mediadores y receptores) que están relacionados entre sí y se modifican con los cambios que se producen en cada uno de ellos, en un movimiento de readaptación continuo.

Trasladando el interrogante propuesto por Chartier para los sociedades del Antiguo Régimen al Nuevo Reino de Granada (¿de qué modo en la sociedad colonial, entre los siglos XVI y XVIII, la circulación multiplicada de lo escrito impreso transformó las formas de sociabilidad, posibilitó nuevos pensamientos, modificó las relaciones con el poder?), el profesor Renán Silva (2008, p. 229-361) dibuja un panorama general del "comercio y circulación del libro en la sociedad colonial" y estudia algunos casos representativos de bibliotecas y lecturas de miembros de la élite cultural ilustrada de finales del siglo XVIII y principios del XIX.

Advierte de ser su análisis un "cuadro general", "aproximativo" o "parcial" por dos principales razones: la dificultad intrínseca del "libro" o el "impreso" como objeto de estudio y el estado "bruto" en que permanecen las fuentes que, a pesar de ser numerosas, todavía no se han investigado, careciendo de análisis preliminares $y$ de indicadores cuantitativos que permitan un acercamiento al estudio de la presencia y funciones del impreso en la sociedad colonial neogranadina desde los enfoques aquí propuestos.

La cuantificación en la historia del libro, por tanto, se hace todavía imprescindible en países como Colombia, pues el retraso de las investigaciones, sobre todo en relación con México y Perú, donde la circulación del libro respecto a otros virreinatos fue mayor, es evidente.

De allí -escribe Chartier para referirse a los historiadores del libro en Francia- la construcción (totalmente necesaria por lo demás) de indicadores capaces de revelar las distancias culturales: así, para un lugar y un tiempo dados, el porcentaje de inventarios póstumos que mencionaban la posesión de libros, la clasificación de las colecciones según el número de obras o incluso la caracterización temática de las bibliotecas privadas en función de la participación que en ellas tenían las diferentes categorías bibliográficas. Desde esta perspectiva, recono- 
cer las lecturas de los franceses de los siglos XVI a XVIII era, ante todo, constituir series de datos cifrados, establecer los umbrales cuantitativos, situar las traducciones culturales de las diferencias sociales. El procedimiento, colectivamente asumido, ha acumulado un saber $\sin$ el cual habría sido impensable la posibilidad de formularse otras preguntas (Chartier, 1995, 109 y 1996, p. 27).

La tardía formación de Nueva Granada como Virreinato (hasta 1717 no se dio la orden para su creación) y la tardía aparición, con un funcionamiento regular, de la imprenta en él (fines del siglo XVIII) son hechos que acentuaron sus diferencias con los virreinatos de México y Perú en cuanto a la variedad y el volumen de libros en circulación. Para mitad del siglo XVII, las capitales de México y Lima ya habían alcanzado las características propias de un gran centro cultural, contando con universidad, imprenta y un buen número de clérigos, funcionarios y profesionales que promocionaban el mercado de lecturas en la ciudad. Con unas fechas aproximadas esta es una relación cronológica de la introducción de la imprenta en algunas ciudades americanas: México (1535), Lima (1581), Manila (1593), Guatemala (1660), Cambridge (1638), La Habana (1724), Bogotá (1777), Quito (1760), Buenos Aires (1780) y Santiago de Chile (1780) (Medina, 1952, p. 9-20; Revello, 1991, p. 138159 y Martínez, 1987, p. 25-29). México, comenta Hampe Martínez (1996, p. 15), obtuvo permiso para imprimir libros y establecer bibliotecas académicas bastante temprano, pero el desarroIlo intelectual en el Perú resultó frenado por los desórdenes de las guerras civiles de los conquistadores y las campañas de represión originadas en el Concilio de Trento (1545-1563). Las instituciones educativas en Perú sólo contaron con apoyo después de que las normas religiosas e ideológicas de la Contrarreforma se hubieran establecido con firmeza.

A estas diferencias contrastadas, contra la circulación del libro y su difusión en esta época (los controles inquisitoriales siempre fueron laxos), de manera cautelosa, el profesor Silva apunta la gran barrera del "analfabetismo de los grupos mayoritarios de la sociedad", donde estaban incluidos muchos de los españoles nacidos en el Nuevo Reino. Si a mitad del siglo XVI, señala Jorge O. Melo (1986, p. 51) a manera de hipótesis, aproximadamente la tercera parte de los conquistadores sabía leer y escribir, para fines de siglo, estos porcentajes pudieron disminuir. Los conquistadores se habían formado en España, mientras que ya a fines de siglo, numerosa población española nace en una sociedad de frontera donde hay urgencias mayores que la del aprendizaje formal. Esta disminución del alfabetismo correría paralela a una disminución del carácter urbano de la población, que "va concentrando el saber formal únicamente en el clérigo, y en ocasiones en el abogado", marcando así a la sociedad colonial que, "junto con el creciente aislamiento cultural de España, mantendrá al Nuevo Reino por fuera de las corrientes científicas de la Europa moderna".

A mediados del siglo XVII la incipiente cultura neogranadina (religiosa, escolástica y filológica) se concentraba en la ciudad de Santafé de Bogotá, que apenas comenzaba su desarrollo urbano. De acuerdo a sus intereses, serán la Iglesia y las órdenes religiosas quienes mayoritariamente pongan en circulación el libro y vayan formando con él sus bibliotecas en una ciudad que por aquel entonces, nos dice Jaime Jaramillo (1977, p. 107-108) retomando la crónica de Lucas Fernández Piedrahita (Historia General del Nuevo Reino de Granada), contaba con tres mil vecinos (españoles y criollos), cerca de diez mil indios, una nutrida burocracia, tres colegios donde el estudiantado es poco dado al estudio de la medicina y las leyes, como sucede en Lima y en México, y mucho a la sagrada teología, la filosofía y las letras humanas, una catedral y más de doscientas ermitas, capillas y oratorios que demuestran el religioso afecto de sus moradores.

Sin olvidar que la difusión de la cultura no se restringía únicamente a los libros (pensemos en las tertulias donde se leían en alta voz pasajes novelescos o en la instrucción de quienes no sabían leer a base de refranes, cuentos, coplas, romances 0 canciones), Máxime Chevalier (1976, p. 19-24) ya habló del alfabetismo en la España de los siglos XVI y XVII (un $80 \%$ de la población: aldeanos y un enorme porcentaje de artesanos) como del gran problema que impedía a la mayoría de la población acceder directamente a la cultura libresca. El elevado costo del papel y de los libros limitaba igualmente a sectores capacitados para leer y escribir como artesanos, hidalgos, funcionarios de medio rango y sacerdotes comunes. Los coleccionistas y lectores de obras se reducían a una élite representada por miembros del alto clero, de la nobleza, los letrados y catedráticos y los ricos mercaderes.

En cuanto a las fuentes documentales que permitan rastrear la circulación del libro y sus implicaciones políticas, sociales y culturales en Nueva Granada, ciertamente, ellas son numerosas. En una simple enumeración podrían citarse las listas de embarque que registraba la Casa de la Contratación, las listas de propiedades confiscadas por la Inquisición, inventarios o catálogos 
de tiendas y mercaderes de libros, los inventarios post mortem (IPM) y testamentos de particulares, los inventarios o catálogos de bibliotecas académicas y de comunidades religiosas, informes, ordenanzas y programas de estudio de universidades y colegios, actas de exámenes, grados y oposiciones a cátedras y curatos, relaciones de méritos y servicios personales, expedientes de confiscaciones y subastas, expedientes de compra-venta, listas de suscriptores de prensa o suscriptores a proyectos de edición de libros, correspondencia institucional y privada, expedientes de autos de bienes de difuntos, repertorios internacionales de la época de obras de autores clásicos, textos litúrgicos, jurídicos, etc., publicaciones de avisos y noticias, repertorios bibliográficos de apoyo a la identificación de obras (Palau, Medina, Adams, British Museum, Sabin, Simón y Aguilar, etc.), la legislación, los catálogos de bibliotecas privadas y públicas actuales (universitarias o religiosas) - a donde, en muchas ocasiones, ha venido a parar el "libro antiguo"-, tratados de poética y retórica, las mismas obras literarias y los estudios histórico-críticos de las mismas, autobiografías, historias de la literatura, relaciones de fiestas y regocijos públicos, etc., etc. Documentación, en definitiva, que ha de proporcionar, en sucesivas investigaciones sistemáticas y en un amplio marco geográfico, una visión mucho más auténtica sobre el influjo que ejerció la divulgación de libros e ideas europeos en el desarrollo social y cultural de Nueva Granada y toda la América hispana.

La mayoría de los investigadores dedicados a estudios relacionados con el mundo de los libros, se ven obligados a comentar las variadas y complejas dificultades teóricas y prácticas que presenta el estudio de las fuentes documentales, pues las propuestas metodológicas están condicionadas por la documentación y sus índices de representatividad como fuente (Lamarca, 1994, p. 17-26; Dadson, 1998, p. 13-48). Dificultades, entre otras, que pasan por cómo medir realmente la importancia del préstamo del libro o la utilización real que se hacía de las bibliotecas, la no aparición de algunos catálogos en los protocolos notariales de bibliotecas realmente existentes, el reflejo fiel o no de listados de libros en los inventarios post mortem o el problema de la identificación de las obras y su exacta cuantificación.

La cuantificación, en cualquier caso, es necesaria como paso previo, pero obviamente, insuficiente, según Manuel Peña (1997, p. 33), para analizar el complejo mundo de las prácticas de las lecturas:
De ahí, que sea más que razonable no olvidar que libro poseído no implica libro leído ni la lectura presupone la obligación de poseer el libro, y que es imprescindible (cuando las fuentes lo permiten) primar el estudio de la circulación sobre la posesión del impreso cuantificable, o el de la sociabilidad de la lectura frente a la posesión privada del libro. Asimismo, es evidente que la tipología de lecturas es múltiple y no se puede reducir a la lectura de los libros. Leer es descifrar todo material impreso o manuscrito, donde ocupan un destacado lugar todos aquellos impresos menores que tuvieron una gran difusión.

\section{Conclusión}

Para analizar en su totalidad la función del libro/impreso en la sociedad colonial de la Nueva Granada, es necesario atender a todos los ámbitos posibles donde circuló y tuvo presencia suficiente: los colegios, seminarios y universidades coloniales de los siglos XVII y XVIII que basaron su enseñanza filosófica en la escolástica; las bibliotecas particulares de quienes pertenecían a un gremio profesional (clérigos, burócratas, juristas, científicos, artesanos); de quienes por su fortuna podían adquirir libros y formar su propia biblioteca como los comerciantes y grandes hacendados; y el ámbito de lo popular, tan complejo de desentrañar en su relación con el impreso y la lectura.

A pesar de ser numerosas las fuentes documentales existentes, a diferencia de otros países suramericanos, todavía en Colombia no se han investigado suficientemente y son escasos los indicadores cuantitativos que posibiliten el estudio del impreso en la sociedad colonial neogranadina desde las actuales perspectivas de la Historia social de la cultura escrita que aquí, a manera de propuesta de investigación, se han relacionado.

\section{Notas}

(1) Sobre historiografía del libro (no se pretende aquí ofrecer un balance riguroso, sólo un panorama general), véanse algunos estados de la cuestión como los de Darnton (2001, p. 189-220), Chartier (1995) y Peña (1996). En la primera sección del segundo, bajo el título genérico de Comparaciones ofrece un balance historiográfico en distintos países: Italia, España, Alemania, los Países Bajos, Inglaterra, Estados Unidos y Rusia. Para el caso de Hispanoamérica véase el Capítulo I —Los horizontes de una aventura historiográfica- de la obra de Carlos Alberto González Sánchez (1999).

(2) Basado en una muestra de más de 2000 libros que en 1605 se embarcaron desde Sevilla hacia México y Perú, González Sánchez (1989, p. 93-104) encuentra el siguiente reparto porcentual temático: libros de ascética y mística $(25,1 \%)$, teología $(16,2 \%)$, catecismos e instrumentos de adoctrinamiento $(13,7 \%)$, poesía y prosa de 
ficción (11\%), regulaciones eclesiásticas $(10,8 \%)$, hagiografías $(4,8 \%)$, materias profanas $(4,5 \%)$ y humanidades $(3,1 \%)$.

(3) A su vez, Márquez Cruz sigue el modelo propuesto por Robert Estivals (1982; 1983, p. 129-164).

\section{Referencias}

Burke, $\mathrm{P}$ (ed.). Formas de hacer historia. Madrid: Alianza, 2001. 189-220.

Darnton, R. (2001). Historia de la lectura. // Burke, P (ed.). Formas de hacer historia. Madrid: Alianza, 2001. 189220.

Castillo Gómez, Antonio (coord.) (2002). Historia de la cultura escrita. Del Próximo Oriente Antiguo a la sociedad informatizada. Gijón: Ediciones Trea, 2002.

Castillo Gómez, Antonio y Sáez, Carlos (1994). Paleografía versus alfabetización. Reflexiones sobre Historia Social de la Cultura Escrita. // Revista de Historia de la Cultura Escrita. 1 (1994) 133-168.

Chartier, Roger (1995). El mundo como representación. Barcelona: Gedisa, 1995.

Chartier, Roger. (dir.) (1995). Histoires de la lecture. Un bilan des recherche., Paris: IMEC Éditions et Éditions de la Maison de l'Homme, 1995.

Chartier, Roger (1996). El orden de los libros. Lectores, autores, bibliotecas en Europa entre los siglos XIV y XVIII. Barcelona: Gedisa, 1996.

Chartier, Roger; Roche, Daniel (1974). Le libre. Un changement de perspective. // Le Goff, J. y Nora, P (dir.). Faire de l'histoire [Troisième partie. Nouveaux objets]. París: Gallimard, 1974. 115-137.

Chevalier, Máxime (1976). Lectura y lectores en la España de los siglos XVI y XVII. Madrid: Turner, 1976.

Dadson, Trevor J. (1998). Libros, lectores y lecturas. Estudios sobre bibliotecas particulares españolas del Siglo de Oro. Madrid: Arco/Libros, 1998.

Estivals, Robert (1983). Le libre dans le monde, 1971-1981: Introduction à la bibliologie politique internationale. $\mathrm{Pa}$ rís: Retz, 1983.

Estivals, Robert (1982). Creation, consommation et production intelectuelles. // Le littéraire et le social: Eléments pour une sociologie de la littérature / Robert Escarpit, ed. París: UNESCO, 1982, p. 129-164

Febvre, L. y Martin, H.-J. (1962). La aparición del libro. México, D.F.: UTEHA, 1962.

García Cárcel, Ricardo (1996). Prólogo a Chartier, Roger. EI orden de los libros. Lectores, autores, bibliotecas en Europa entre los siglos XIV y XVIII. Barcelona: Gedisa, 1996. 9-17.

García López, Genaro Luis (2003-04). Las investigaciones sobre el libro y las bibliotecas desde un punto de vista histórico, sociológico y educativo. // Litterae: Cuadernos sobre Cultura Escrita. 3-4 (2003-04) 259-263.

Gimeno Blay, Francisco M. (1999). De las ciencias auxiliares a la Historia de la Cultura Escrita: Seminari Internacional d'Estudis sobre la Cultura Escrita. València: Departament d'Història de l'Antiguitat de la Cultura Escrita. U.D. Paleografia. Universitat de València, 1999.
González Sánchez, Carlos Alberto (1989). El libro y la carrera de indias: registro de ida de navíos. // Archivo hispalense: Revista Histórica, literaria y artística. 72:220 (1989) 93-104.

González Sánchez, Carlos Alberto (1999). Los mundos del libro. Medios de difusión de la cultura occidental en las Indias de los siglos XVI y XVII. Sevilla: Universidad y Diputación de Sevilla, 1999.

Gutiérrez Girardot, Rafael (1989). Temas y problemas de una historia social de la literatura hispanoamericana. Bogotá: Ediciones Cave Canem, 1989.

Hampe Martínez, Teodoro (1996). Bibliotecas privadas en el mundo colonial. La difusión de libros e ideas en el virreinato del Perú (siglos XVI-XVII). Madrid: VervuertFrankfurt-lberoamericana, 1996.

Jaramillo Uribe, Jaime (1977). La personalidad histórica de Colombia y otros ensayos. Bogotá: Instituto Colombiano de Cultura, 1977.

Lamarca Langa, Genaro (1994). La cultura del libro en la época de la ilustración. Valencia, 1740-1808. Valencia: Edicions Alfons el Magnànim-Instituciò Valenciana d'Estudis i Investigaciò, 1994.

Márquez Cruz, Guillermo (1988). Sociología del libro y de la lectura: la comunicación cultural en Andalucía. Primera parte: Metodología. // Boletín de la Asociación Andaluza de Bibliotecarios. 4:10 (enero-marzo 1988) 5-19.

Martínez, José Luis (1987). El libro en Hispanoamérica. Origen y desarrollo. Madrid: Fundación Germán Sánchez Ruipérez-Pirámide, 1987.

Medina, José Toribio (1952). La imprenta en Bogotá y la Inquisición en Cartagena de Indias. Bogotá: Biblioteca Nacional de Colombia, 1952.

Melo, Jorge Orlando (1986). La cultura durante el periodo colonial. // Friede, Juan; Jaramillo Uribe, Jaime; Melo, Jorge Orlando y Recasens, José de. Cultura colombiana. Contribuciones al estudio de su formación. Bogotá: Instituto Colombiano de Cultura, 1986. 29-58.

Parada, Alejandro E. (2007). Cuando los lectores nos susurran. Libros, lecturas, bibliotecas, sociedad y prácticas editoriales en la Argentina. Buenos Aires: Facultad de Filosofía y Letras (Instituto de Investigaciones Bibliotecológicas). Universidad de Buenos Aires, 2007.

Peña Díaz, Manuel (1996). Cataluña en el Renacimiento: libros y lenguas (Barcelona, 1473-1600). Lleida: Ed. Milenio, 1996.

Peña Díaz, Manuel (1997). El laberinto de los libros. Historia cultural de la Barcelona del Quinientos. Madrid: Fundación Germán Sánchez Ruipérez-Pirámide, 1997.

Petrucci, Armando (2003). La ciencia de la escritura. Primera lección de paleografía. México DF: Fondo de Cultura Económica, 2003.

Silva, Renán (2008). Los ilustrados de Nueva Granada, 1760-1808. Genealogía de una comunidad de interpretación. Medellín: EAFIT, 2008.

Torre Revello, José (1991). El libro, la imprenta y el periodismo en América durante la dominación española. México DF: Universidad Nacional Autónoma de México, 1991. 
